\title{
LAS VIRTUDES JUDICIALES Y LA NOVELA UN JUEZ RURAL DE PEDRO PRADO: APUNTES PARA UN PROBLEMA IDEOLÓGICO
}

\author{
THE JUDICIAL VIRTUES AND THE NOVEL A RURAL JUDGE BY PEDRO PRADO. \\ NOTES FOR AN IDEOLOGICAL PROBLEM
}

Claudio agüero San Juan

Fecha de recepción: 4 de mayo de 2010.

Fecha de aceptación: 5 de junio de 2010.

\begin{abstract}
Resumen
El artículo revisa el problema de la evaluación moral de la judicatura a partir de las relaciones entre Derecho y Literatura. Desarrolla la posición de Alisdair Maclntyre sobre las virtudes y revisa cómo la novela chilena Un juez rural de Pedro Prado puede considerarse una forma de expresión del punto de vista macintyriano. Finaliza, mostrando cómo cualquier evaluación moral del rol judicial es, a $\forall n$ de cuentas, la manifestación de una ideología.

Palabras clave: Maclntyre, virtudes judiciales, Un juez rural.
Abstract
The article reviews the problem of moral assessment of the judiciary from the relationship between law and literature. Develop Alisdair MacIntyre's posi- Prado can be considered a form of expression macintyriano point of view. End, showing how any moral evaluation of the judicial role is, after all, the manifestation of an ideology. tion on the virtues and reviews how the Chilean novel A rural judge of Pedro
\end{abstract}

Key words: Maclntyre, judicial virtues, A rural judge.

Oliver Wendell Holmes

Abogado, Licenciado en Ciencias Jurídicas de la Universidad Católica de Temuco, Magíster en Educación, Universidad de La Frontera.

Académico Escuela de Derecho, Universidad Católica de Temuco

Mail: aguero@uct.cl 


\section{Introducción}

Según François Ost es posible comprender la relación entre el Derecho y la Literatura de tres formas: el Derecho de la Literatura, el Derecho como Literatura y el Derecho en la Literatura. La primera, se interesa por el estudio de la libertad de expresión y de la censura como fenómenos jurídicos asociados a la publicación de libros como, Werther, Madame Bovary o Los versos satánicos. La segunda, analiza las dimensiones retórica y narrativa del discurso jurídico con las herramientas propias de la crítica literaria y del análisis narratológico. La tercera, estudia cómo las obras literarias recepcionan ciertas concepciones normativas -jurídicas y morales- sobre la Justicia, los Derechos Fundamentales o el Poder Político ${ }^{1}$. El presente trabajo se integra a esta última forma de comprender la relación entre el Derecho y la Literatura, mediante el análisis de la novela Un juez rural del escritor chileno Pedro Prado. Su objetivo es proponer que 'la persecución de la prudencia' como virtud -en su versión comunitarista postulada por Maclntyre ${ }^{2}$ es la matriz de la novela y la forma más adecuada para comprender la obra de Prado de forma unitaria, ya que permite enfrentar a la interpretación tradicional de la crítica literaria nacional que ha visto en ella una historia fracturada en dos fragmentos divididos por la renuncia al cargo de juez del protagonista $^{3}$.

Mi hipótesis es doble, por un lado afirma que la comprensión comunitarista de la virtud de la prudencia se expresa de forma alegórica en novela ${ }^{4}$-cuestión que ha sido omitida por la crítica nacional-, y por otro, postula que la revisión de obras literarias permite, al lector atento, captar las ideologías sobre la administración de justicia que circulan en la sociedad. Para falsear esta hipótesis mi argumentación procederá en tres pasos: primero desarrollaré el modelo de las virtudes según Maclntyre mostrando el rol de la prudencia; luego, analizaré la búsqueda de la prudencia en la novela interpretando algunos acontecimientos de la historia y la construcción del personaje protagónico como manifestaciones de la idea de 'estructura narrativa de la vida' del comunitarismo macintyriano. Finalizaré con unas palabras de cierre, las que se concentrarán en formular el carácter ideológico de la crítica moral de la tarea judicial.

François Ost, "El reflejo del Derecho en la literatura", Revista Doxa de Teoría y Filosofía del Derecho 29 (2006), pp. 334-336.

2 Alasdair MacIntyre, Tras la virtud (Barcelona: Crítica, 1987).

3 Julio Arriagada y Hugo Goldsack, "Pedro Prado, un clásico de América". Revista Atenea de la Universidad de Concepción (Chile) 321, 322, 323, 324 (1952)

4 Gerald Genette, "El discurso del relato", en Figuras III (Barcelona: Lumen, 1986). 


\section{El modelo de las virtudes de MacIntyre}

En 1984, Alasdair Maclntyre publicó After Virtue (Tras la virtud), donde postuló que Occidente había perdido una visión ética coherente y sistemática sobre los problemas morales, debido al fracaso del proyecto ilustrado que intentó romper todos los fundamentos metafísicos explicando racionalmente los fenómenos sociales. Frente a esta crisis de la ética, Maclntyre propuso retomar la tradición aristotélico-tomista de las virtudes abandonando la ética kantiana de reglas universales para fundar un proyecto ético en tres conceptos: las 'prácticas sociales', la 'estructura narrativa de la vida humana' y la 'tradición moral'.

Maclntyre definió 'práctica social' como una actividad humana cooperativa, compleja y socialmente establecida, cuyo ejercicio permite que los practicantes logren bienes internos a la actividad según el modelo de excelencia que define al bien prácticamente y otros bienes externos a ella ${ }^{5}$.

Son bienes internos aquellos que pueden ser adquiridos por los practicantes solo mediante el ejercicio de la práctica en cuestión y cuyo logro favorece el florecimiento de toda la comunidad, mientras que, son bienes externos los que pueden ser adquiridos por el ejercicio de varias prácticas alternativas y que generan un beneficio exclusivo para su propietario. Según Maclntyre, los bienes internos se realizan a través de las virtudes pues el ejercicio de la virtud permite adquirir el bien y mejorar la actividad colaborativa de la comunidad a través del seguimiento del modelo de excelencia de la práctica, es decir, mediante la persecución del patrón de conducta que contiene las normas de evaluación del desempeño de los practicantes y que por ello define al buen practicante.

Con este concepto de 'práctica social', Maclntyre ofrece un primer acercamiento a la idea de virtud cuyas funciones son: mostrar la necesidad de las virtudes como formas de acceso a los bienes contenidos en las prácticas y hacer notar que las virtudes definen las relaciones entre las personas que comparten un propósito y un modelo de excelencia:

"Una virtud es una cualidad humana adquirida, cuya posesión y ejercicio tiende a hacernos capaces de lograr aquellos bienes que son internos a las prácticas y cuya carencia nos impide efectivamente el lograr cualquiera de tales bienes" ${ }^{6}$.

El segundo concepto es 'la estructura narrativa de la vida'. Siguiendo a Aristóteles, Maclntyre postuló que la búsqueda de la vida buena es la principal tarea de la ética. Para él, esta búsqueda otorga a la existencia humana la estructura de una narra-

5 Maclntyre, Tras la virtud, p. 233.

6 Ibíd, p. 327. 
ción dramática en tres sentidos: primero, cada persona -al igual que un personaje literario- cuenta con una historia de vida, puede tomar ciertas decisiones y enfrenta un futuro que puede resultar exitoso o frustrado ${ }^{7}$. En segundo lugar, los problemas morales se consideran problemas narrativos, es decir, los actos morales solo pueden ser entendidos si se aprecian como acontecimientos que integran la historia de persona ${ }^{8}$. En tercer lugar, las personas -en tanto agentes morales- usan las narraciones como una estrategia epistémica y ética, mediante la cual aprenden el discernimiento moral y los roles sociales; ordenan, dan sentido y orientan sus decisiones, y comprenden las decisiones morales de otros ${ }^{9}$.

La tradición moral es el tercer concepto en el que Maclntyre apoya su teoría sobre las virtudes. Ella se define como el contexto dentro del cual se desarrolla la vida de las personas. La vida buena solo se logra mediante las prácticas sociales y ellas solamente pueden comprenderse en el marco de la tradición moral de la comunidad. La persona (para Maclntyre) es inseparable de su comunidad pues en ella se desarrolla su vida, se cultivan las virtudes, se aprende a ser agente moral y, en definitiva, se transita el camino hacia la excelencia moral ${ }^{10}$. La tradición es, entonces, la reunión de las historias de los individuos en una narración mayor que les otorga a ellas identidad comunal.

Esta forma narrativa de conseguir la perfección moral supone que la vida moral se concibe como una unidad. Si la vida moral tiene una 'estructura narrativa' a nivel personal y colectivo, las personas son, al mismo tiempo, hijos, padres, ciudadanos y profesionales. Por ello, sus acciones no pueden ser aisladas (posición defendida por la filosofía analítica), ni consideradas como manifestaciones de personajes diferentes (al modo de la filosofía existencialista) ya que esas opciones implican diluir el integridad telos del proyecto personal de vida buena, es decir, separar el concepto de lo bueno del hombre mismo. Este telos es la excelencia moral que permite comprender "lo que la vida buena para el hombre es" 11.

Aspirar a una vida virtuosa es buscar tener una existencia digna de ser narrada, y esta persecución -en tanto inherente a la naturaleza humana- impone que la 'estructura narrativa de la vida' gire en torno al valor de la prudencia entendida como phronesis (EN 1138b25) ya que, paradójicamente, el hombre siendo un ser racional es, al mismo tiempo, un ser falible. Tal como señala De la Torre:

"La prudencia es la clave de todas las virtudes. Sin ella no es posible ser virtuoso (sí obediente a la norma). Un hombre puede tener excelentes principios,

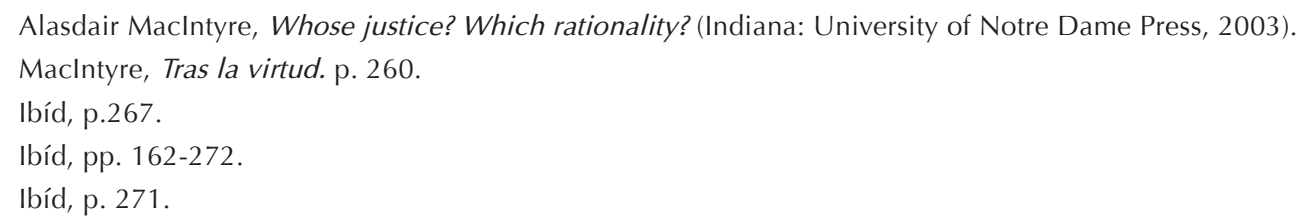


pero no actuar de acuerdo con ellos [...] La prudencia supone captar el verdadero telos del hombre y saber los casos en que hemos fracasado" 12 .

Teniendo estas ideas a la vista, Maclntyre define las virtudes como:

"aquellas disposiciones que no sólo mantienen las prácticas y nos permiten alcanzar los bienes internos a las prácticas, sino que también nos sostienen en el tipo pertinente de búsqueda de lo bueno, ayudándonos a vencer los riesgos, peligros, tentaciones, y distracciones que encontremos y procurándonos creciente auto-conocimiento y creciente conocimiento del bien" ${ }^{13}$.

De este modo, Maclntyre presenta una crítica al individualismo epistemológico y a la modernidad racionalista ilustrada porque las virtudes no pueden ser alcanzadas individualmente debido a que las 'prácticas sociales' son siempre comunales. Así, es necesario que las personas se eduquen en la virtud de la prudencia y que se orienten en la tradición moral de la comunidad para que puedan lograr la excelencia moral.

\section{La novela}

La historia de la novela cuenta eventos de la vida del arquitecto Esteban Solaguren, que transcurren en poco más de dos meses en un tiempo y lugar parcialmente indefinidos. La secuencia de los acontecimientos permite apreciar una diégesis lineal compuesta de cuatro partes bien definidas: presentación del personaje y de su contexto, actuación como juez del protagonista, renuncia al cargo, y la narración de aspectos psicocognitivos del protagonista en los últimos capítulos de la novela.

Como he dicho más arriba, esta estructura ha motivado a la crítica literaria nacional para postular que la renuncia divide la historia en dos. Sobre el particular, Arriagada y Goldsack han señalado:

"Es curioso advertir que todos, engañados por el título, vean en esta novela simplemente las peripecias jurídico-morales de un juez de subdelegación, en circunstancias de que ella consta de dos partes bien definidas: la primera, que ya conocemos en general, y una segunda que no guarda ninguna relación con aquélla y en la que Prado cuenta algunas experiencias psicológicas personales y de gran interés" 14 .

\footnotetext{
12 Francisco Javier de la Torre Díaz, Alisdair Maclntyre ¿un crítico del liberalismo? (Madrid: Dykinson, 2005), p. 215.

13 MacIntyre, Tras la virtud, p. 270.

14 Arriagada y Goldsack, "Pedro Prado, un clásico de América", p. 274.
} 
Si bien el título de la novela hace referencia a la tarea de administrar justicia, existen varias evidencias que permiten postular que la historia se construye en torno a una alegoría a las virtudes.

La caracterización fictiva del actuar judicial del protagonista, ubica a un arquitecto en un juzgado de subdelegación resolviendo los casos 'a conciencia' y permite que la diégesis se aleje de la realidad judicial chilena de la época. Esta distancia permite, en mi opinión, juzgar que la novela no es una obra realista o costumbrista pues, por una parte, la sustitución del trabajo arquitectónico por el trabajo judicial en conciencia parecer ser una alegoría del abandono de la ética kantiana basada en principios universales y la asunción de la ética comunitaria y, por otra parte, porque la ficción del actuar judicial 'a conciencia' no siendo posible en la realidad, posiciona simbólicamente a Solaguren por sobre el derecho positivo mediante su liberación de las obligaciones prototípicas que el juzgador tiene en los sistemas jurídicos liberales: interpretar la ley y valorar los medios de prueba.

Esta opinión se confirma si la construcción del personaje protagónico en su dimensión profesional y personal se entiende como una estrategia literaria para mostrar la tensión entre la ética kantiana propia en la urbanidad postilustrada y la tradición ética comunal propia de la ruralidad agraria. La ubicación de un arquitecto (profesión liberal propia de la ciudad) en la posición social de juez, es decir, evaluador de los comportamientos ajenos en una comunidad agraria, desarrolla, a mi juicio, la idea de autoridad moral del juzgador y de su necesaria integración con la vida de los justiciables, cuestión que parece quedar en evidencia en la tensión que el ejercicio de la judicatura provoca en el temperamento melancólico y socialmente retraído de Solaguren, quien solo consigue la tranquilidad emocional en la pintura, en sus paseos por el campo y en ciertos momentos de soledad. Así, la novela cobra unidad si se aprecia que la diégesis y las metadiégesis giran en torno a las virtudes y a los estados doxásticos (creer, dudar, etc.) del protagonista, donde la prudencia es mediador ético y epistémico porque la moralidad de las acciones se deriva de la moralidad de los estados internos del agente. Por ejemplo, al inicio de la obra, el narrador relata a propósito de un incidente entre Solaguren y sus hijos: "Solaguren volvía lentamente a su tranquilidad. Entristecido, sentíase injusto con sus hijos" (p. 10). Posteriormente, en una noche de insomnio, el soliloquio del protagonista se dirige a los principios del razonamiento expuesto en Xenofontes (sic) y exclama: "iRepugnante llegar y llegar a conclusiones satisfechas de sí, como si fuesen, en verdad, las últimas y definitivas!". Luego, el narrador nos cuenta: "Sentía con meridiana evidencia la insulsez de lo que leyera, y todas las leyes del pensamiento ofrecíansele de golpe, nítidas, brillando en una intuición total que las abarcaba por completo" (p. 38) ${ }^{15}$.

15 Pedro Prado, Un juez rural (Santiago: Editorial Universitaria, 1996). 
Estos fragmentos muestran la reflexión moral del protagonista, y la relación que la novela establece entre la reflexión ética y los estados emocionales. Las cavilaciones del protagonista evidencian entonces el rechazo del modelo de razonamiento práctico basado en reglas universales (representado simbólicamente por el libro de Xenofontes) y del cual derivan las ideas de deberes y derechos individuales ${ }^{16}$. Acoge, en cambio, la intuición moral como camino para la resolución de los problemas éticos que le presentan los casos judiciales.

Es el sentimiento de lo bueno lo que permite al protagonista el acceso a la plena comprensión de las virtudes en tanto bienes objetivos manifestados en la narratividad de la vida en comunidad. Por ello, al fallar el protagonista aprecia en las historias de vida de los personajes el ejercicio virtuoso (o no) de la práctica social que da forma a cada uno de los conflictos y valora la narración de lo ocurrido que realizan los justiciables libre de buscar pruebas sobre su verdad. De esta forma, la prudencia se convierte en la herramienta epistemológica que permite al juez comprender el rol de la virtud en el relato de cada caso.

Otra manifestación de la narratividad ética es el acto mismo de renuncia al cargo de juez. La imposibilidad práctica de valorar positivamente las virtudes de los justiciables (premiar las conductas) y la fuerza de las relaciones interpersonales y/o comunitarias operan en el protagonista como razones absolutas en sentido aristotélico, es decir, como razones que motivan con tal fuerza la decisión de renunciar que la reflexión y más aún la abstención de la acción implican, desde su subjetividad, la irracionalidad. Este compromiso con la virtud, propio del razonamiento aristotélico, se exhibe en las consecuencias que la narración de la madre del ladrón tiene en Solaguren, quien se muestra desesperado y confundido. La metadiégesis de su carta de renuncia muestra la tensión entre las tradiciones éticas (la kantiana y la aristotélica) presentes en la obra:

"Mi desesperación, señor Intendente, proviene de que no puedo aislar un individuo, el culpable, y castigarlo solo a él... Parece, señor Intendente, que nuestras leyes se basan en el concepto de individuo, y ese concepto se me hace sospechoso: un individuo que no limita ¿qué individuo es? Su cuerpo aislado nos engaña con su apariencia independiente, no puedo aislar un individuo, el culpable, y castigarlo solo a él... Parece, señor Intendente, que nuestras leyes se basan en el concepto de individuo, y ese concepto se me hace sospechoso: un individuo que no limita ¿qué individuo es? Su cuerpo aislado nos engaña con su apariencia independiente. ¿Sobre qué base fundar la verdadera justicia?" 17.

16 De la Torre Díaz, Alisdair Maclntyre ¿un crítico del liberalismo?, p. 214.

17 Prado, Un juez rural. p. 168. 


\section{Palabras al cierre (la ideología)}

Hay temas interesantes que la novela me sugiere y que no he podido tratar aquí. Quiero destacar tres de ellos: la tensión entre el estado emocional de Solaguren y las virtudes doxásticas, es decir, la relación entre la soledad y la pesadumbre con un determinado estado de creencia ingenua, escepticismo o dogmatismo; segundo, como la prudencia media (o no) entre la emocionalidad y las virtudes doxásticas; tercero, la relación simbólica y alegórica entre las actividades que desarrolla el protagonista; la arquitectura, la pintura y la justicia, por un lado, y la creación, representación, presentación del mundo y de la comunidad, por otro.

Parece necesario destacar cómo la lectura éticamente atenta de novela en estudio permite al lector cultivar lo que Martha Nussbaum ha Ilamado imaginación literaria', esto es, "una imaginación pública, una imaginación que sirva para guiar a los jueces en sus juicios, a los políticos cuando midan la calidad de vida de gentes cercanas y lejanas ${ }^{\prime \prime 8}$. En palabras de Nussbaum, la lectura de novelas a través de argumentos, teoría moral y política permite desarrollar esta imaginación que evita que la imparcialidad sea obtusa y la justicia ciega, ya que 'fantasear', más allá de sus aptitudes técnicas, ayuda a comprender el conflicto y a sus participantes ${ }^{19}$. Por otro lado, en contra de esta idea general, Jorge Malem ha postulado que el juez "ha de huir de las adjetivaciones excesivas y del uso de metáforas. Y no debe referir a mundos imaginarios o a cuestiones para las que carece de estricta competencia jurídica. Decididamente, el juez no se puede comportar como un literato, aunque comparta con él la necesidad de conocimiento de la lengua que utiliza en su trabajo"20.

A mi juicio, ambas posiciones se muestran como ideologías sobre la administración de justicia, porque toda evaluación moral es expresión de nuestras creencias y, habitualmente, ellas están al servicio de algún poder inconfeso. Así, la diferencia entre Nussbaum y Malem es solo aparente. Una enfatiza la noción de razonamiento práctico, individualista de inspiración kantiana y la otra prefiere a la intuición moral como medio de resolución de problemas morales y jurídicos. La apariencia radica en que ambas, a fin de cuentas, conducen a la valoración de las conductas de los jueces. Esto es así, porque tanto para Nussbaum como para Malem la creencia en virtudes judiciales no es solo un estado mental 'íntimo' del juez, sino que esa creencia se "materializa en la actividad social efectiva: la creencia sostiene la fantasía que regula la realidad social' 21 . En otras palabras, los jueces no son 'buenos jueces' porque crean

18 Nussbaum, Martha. Justicia Poética (Madrid: Editorial Andrés Bello, 1997), p. 27.

19 Ibíd., p. 163.

20 Jorge Malem, El error judicial y la formación de los jueces (Barcelona: Gedisa, 2008), p. 238.

21 Slavoj Žižek, “¿Cómo Marx creó el síntoma?”, en Ideología, Un mapa de la cuestión (Argentina: Fondo de Cultura Económica, 2008), p. 353. 
en la justicia o cultiven alguna virtud judicial, sino que la creencia se justifica en una previa conducta judicial correcta, que es previa al estado de creencia. De este modo, solo encontramos razones que justifican o confirman nuestras creencias en un determinado conjunto de virtudes judiciales únicamente una vez que ya creemos en ellas; no es que creamos porque hayamos descubierto buenas o novedosas razones para creer. Esta forma de ver el problema nos da una nueva clave de lectura de la novela. Solaguren decide ser juez (y decide renunciar) porque ya cree en un cierto conjunto de virtudes y no al revés.

\section{Bibliografía}

Arriagada, Julio y Hugo Goldsack. "Pedro Prado, un clásico de América" Revista Atenea de la Universidad de Concepción (Chile) 321, 322, 323, 324 (1952).

De la Torre Díaz, Francisco Javier. Alisdair Maclntyre ¿un crítico del liberalismo? Madrid: Dykinson, 2005.

Genette, Gerald. "El discurso del relato", en Figuras III. Barcelona: Lumen, 1986.

Macintyre, Alasdair. Tras la virtud. Barcelona: Crítica, 1987.

- Whose justice? Which rationality? Indiana: University of Notre Dame Press, 2003.

Malem, Jorge. El error judicial y la formación de los jueces. Barcelona: Gedisa, 2008.

Ost, Françols. "El reflejo del Derecho en la literatura". Revista Doxa de Teoría y Filosofía del Derecho 29 (2006).

Prado, Pedro. Un juez rural. Santiago: Editorial Universitaria, 1996.

ŽıžEK, Slavoj. “¿Cómo Marx creó el síntoma?”, en Ideología, Un mapa de la cuestión. Argentina: Fondo de Cultura Económica, 2008. 